\title{
Planning of the Human Resources in the Jordanian Banks by using Markov Models
}

\author{
Dr. Laith Abdallah Alqheiwi \\ Assistant Professor / Department of Business Administration \\ Faculty of Economics and Administrative Sciences /Zarqa University \\ laith_alkhaiwi@yahoo.com,lqhaiwi@zu.edu.jo
}

*This research is funded by the Deanship of Research in Zarqa University/ Jordan.

\begin{abstract}
This study aims to explain the Markov Models and its application in order to analyze the movement of the HR in the Jordanian Banks. To achieve the objectives, the study is depend on the secondary data related to Human Resources selected from the annual reports of the Jordanian Banks (Arab Bank, Housing Bank, and Jordan Bank) for year (2014). The study reached at a number of results, which are the estimation of the transition probabilities, refers to the highest retention percentage was in favor of the Arab Bank, followed by Housing Bank, and finally followed by the Jordan Bank, also the estimation of the transition probabilities, refers to the lowest loss was in favor of the Arab Bank, for Housing Bank and Jordan Bank. Upon the foregoing results, the study reached to a number of conclusions.
\end{abstract}

Keywords: Human Resources (HR) Planning, Markov Models, Transition Probabilities, Jordanian Banks.

\section{INTRODUCTION}

As a result of the development in the economic, technological and social field, had the subject of the Human Resources planning and widely watched by politicians, administrators and economists, and because of the demonstrated this development of a significant shortfall HR resulting in a planning consideration of the Human Resources a props and basic pillars of economic development plans, where you specify the dimensions this process in the light of the mobilization of manpower and appropriate efficient distribution and use of the various economic sectors, which collectively contribute to the economic development process (James, 2007: 214).

In light of the foregoing, the aim of the Human Resources planning is to meet the future requirements of the labor force or what is available in the future in light of the multiple objectives such as economic conditions, governmental and instructions as well as the history of the facility and its policies regarding recruitment, promotion and dropout.

The HR planning on the basis of established process requires a good knowledge of those deployed in the establishment, as well as entry and dropout and promotion of employees in order to reach a future plan fit and desire administration in determining the future policies of the Human Resources system. As the number of employees at the facility is fixed where noted that this number will increase to the gallery by the entry of new employees of the establishment or system to represent (gain for establishment), or exposed to decrease due to the leakage of workers outside the entity to represent the (loss for establishment). As a result of this movement of workers, and the movement of entering and there leakage. To achieve that can be used Markov Analysis, which is one of the easiest method to describe a movement of the employees and thus predict the numbers of the employees within the enterprise, and using the transition probabilities' matrix that seem more accurate in the Human Resources planning (Touama, 2015).

\section{Methodology}

\subsection{The Study Problem}

The study problem involving about the suffering many of the Jordanian banks of the labor turnover problem, and that will certainly affect on the policies, plans, and the institutional performance of these banks. In order to handle with this problem should working, including the following: 
a. The need of the Jordanian banks departments using some scientific methods and mathematical models for human resource planning in them.

b. Selection of appropriate models for this kind of the problem, for example, Markov models.

c. Predict by the human resources that you need these banks in the future periods.

\subsection{The Study Objectives}

The objectives of this study can be explained as follows:

a. To identify the HR planning concept for the organizations, importance of the HR planning, and the objectives of the HR planning.

b. To identify the Markov models concept, estimate the Markov matrix, and explained the market equilibrium conditions.

c. To forecast the numbers of employees at the years (2015 and 2016), and forecast the number of the $\mathrm{HR}$ at the Market Equilibrium.

\section{THEORETICAL FRAMEWORK}

\subsection{HR Planning Concept}

Has become a study of the HR and Planning of important topics, to the importance enjoyed by the HR as a factor leading producer and engine of the natural resources on the one hand, and the impact and the importance of the Human Resources planning in achieving economic development as a whole on the other hand the process.

The human resources planning process includes, the forecasting by the organization needs of the human resources by estimating the demand and supply of labor, and in addition to that, the human resources planning process aimed at finding appropriate mechanisms that will help the organization to bridge the gap between the desired employment and the supply of, in other words, the process of the human resources planning aims to identify the quantity and quality of the human labor, which should accede to the organization or come out of it.

In light of the foregoing, the aim of the HR planning is to meet the future requirements of the labor force or what is available in the future in light of the multiple objectives such as economic conditions, governmental and instructions as well as the history of the facility and its policies regarding recruitment, promotion and dropout.

\subsection{The Importance of Human Resources Planning}

The organization is seeking from human resources planning process to achieve the following (AlTaai, 2006: 158):

- Helps planning of human resources in the prevention of sudden stops or deficit in the production line and the implementation of the project.

- Helps HR planning to get rid of surplus and plug.

- The planning of human resources before and human resources management functions.

- Assist in the integration and interdependence between the various human resources management software.

- Helps to show the strengths and weaknesses in the quality and performance of human resources.

- Leads to a balance between the activities and functions of human resources management and general objectives of the organization.

- Prepare the organization for any changes that may occur in the internal and external environment, and to face any repercussions may occur in the work content or quality of individuals as a result of those changes.

- The provision of human resource needs the overall strategy of the organization in a balanced work force with the required volume of work. 


\subsection{Objectives of the Human Resources Planning}

The main objectives, which calls attention to human resources planning as follows (Kashwy, 2006: 24):

- Take advantage of workers who were employed full advantage.

- Ensure that the foundation is able to ensure that all employees receive the necessary training and development, to raise the efficiency of performance in current tasks their positions.

- Ensure that the institution is able to anticipate and act on the change in the demand for services provided by the institution, or the change in the labor supply.

- That the institution be able to meet the future requirements of human resources from internal resources.

- Ensure that the institution confirms to provide equal opportunities for promotion and development of all staff.

- Ensure that the institution control to control the human resources costs, and expects a degree of efficiency in personnel expenses of any new initiatives.

- Maintaining the energies of workers and invest and promote motivation to work, and the ways that ensure their progress and career development.

- The preparation of human resources budget both in the field of employment, training or services and end services.

\subsection{Markov Models}

Markov Models is a best quantitative method, whereby the analysis of the current changes to the phenomenon that, in order to predict future changes to this phenomenon (Barry, et al., 2000).

The Markov processes is a special case of stochastic or random processes, and look for these operations as a series of situations experienced by the phenomenon through a certain period of time or processes through which a moving object through different periods of time series, called the mentioned operations series by (Markov Chains). In order to identify the Markov Models must be used mathematical analytical methods and conclusions and to clarify the distinctive properties during the development process (Sirl, 2005: 1),

Based on the foregoing, the Markov Models defined as a "mathematically and scientific method to analysis of the behavior of different phenomena's during the current period in order to predict the behavior of these phenomena's in the future in any later periods" (Touama, 2009: 297).

\subsubsection{Markov Matrix}

The traditional status of the transition probabilities $\left(\mathrm{P}_{\mathrm{ij}}\right)$ values putting in a square matrix $\mathrm{P}=\left[\mathrm{P}_{\mathrm{ij}}\right]$, which takes the following form (Touama, 2009: 299-300):

This matrix sometimes called (Transition Probabilities' Matrix), which represents the matrix of the stochastic or random processes, in which the sum of the probabilities of any row equal to the one $\left(\sum \mathrm{P}_{\mathrm{ij}}=1, \mathrm{i}=1,2, \ldots, \mathrm{m}\right)$.

In order to obtain the Markov Matrix, we find the following terms:

\section{a. Retention Ratio}

It means that the organization's ability to retain with a greater percentage of its customers, and it calculated by the following formula:

$\mathrm{P}_{\mathrm{ii}}=1-\mathrm{L}_{\mathrm{i}} / \mathrm{V}_{\mathrm{i}}$

Whereas:

$\mathrm{P}_{\mathrm{ii}}$ : Retention ratio by the customers for the organization (i).

$\mathrm{L}_{\mathrm{i}}$ : The customers number are losing of the organization (i).

$\mathrm{V}_{\mathrm{i}}$ : The customers number at the starting period of the organization (i). 


\section{b. Loss Probability}

It means the loss probability of the organization to it's customers to other organizations, and it calculated by the following formula:

$\mathrm{P}_{\mathrm{ij}}=\mathrm{N} / \mathrm{V}_{\mathrm{i}} \quad, \quad \mathrm{j}=1,2, \ldots, \mathrm{n}$

Whereas:

$P_{i j}$ : Loss probability of the organization (i) to the organization (j).

$\mathrm{N}$ : The customers number are losing of organization (i) to other organizations.

\subsubsection{Forecasting in the Market Shares}

We can determine the share of each organization in the current period, by the following formula (Touama, 2009: 304):

$\mathrm{S}_{(\mathrm{i})}=\mathrm{V}_{\mathrm{i}} / \sum \mathrm{V}_{\mathrm{i}}$

Whereas:

$\mathrm{S}_{(\mathrm{i})}$ : Market share of the organization (i) in the current period.

$\sum \mathrm{V}_{\mathrm{i}}$ : Sum of customers at the starting period.

After that we can forecast the Market shares for subsequent periods, by using the following form:

$\underline{S P}=\underline{S}$

\subsubsection{Market Equilibrium Conditions}

We can reach a state of the market equilibrium, through the following relations:

a. Assume that we have the row probability vector ( $\underline{S})$, representing the market shares to $(\mathrm{m})$ organizations, this means that (Touama, 2009: 307-309):

$\underline{\mathrm{S}}=\left[\mathrm{S}_{1}, \mathrm{~S}_{2}, \ldots, \mathrm{S}_{\mathrm{m}}\right], \quad \sum \mathrm{S}_{\mathrm{i}}=1$

b. Assume that we have the market shares matrix $\mathrm{P}=\left[\mathrm{P}_{\mathrm{ij}}\right]$, therefore re-use and solution the previous relations, can be reached to the state of the market equilibrium, as follows:

$\mathrm{S}_{1}+\mathrm{S}_{2}+\mathrm{S}_{3}+\ldots . .+\mathrm{S}_{\mathrm{m}}=1$

$\underline{\mathrm{S}} \mathrm{P}=\underline{\mathrm{S}}$

In order to solve the previous linear equations system in (6) and (7), should delete one of these equations for getting $(\mathrm{m})$ of equations equal to the variables number $(\mathrm{m})$.

After solving the linear equations system of (m) equation, we will get the row probabilistic vector (S), and this vector represents the market equilibrium conditions, and the values of the row probabilistic vector indicate to the organizations' shares in period of the market equilibrium.

c. Determine the customer's number in period of the market equilibrium, by using the following form:

Number of customers $=\mathrm{S}_{\mathrm{i}} *\left(\sum \mathrm{V}_{\mathrm{i}}\right) \%$

\section{LITERATURE REVIEW}

- Study of (Al-Bayaa, 2003), entitled: Registry errors in Markov chains: An Empirical Study for dairy products.

This study aimed to interpret the idea of errors and random simplified and explained the difference between them and the random errors and also get to know one of the most important and most dangerous mistakes is random registry errors and explain the potential appreciation and predict its path and amount through Markov chains, the study found several results of the most important: it is impossible to eliminate the random error term that spread necessarily mean to discredit estimates and forecasts resulting from the use of Markov chains, and this will be supported away basis primarily on the error term, and take advantage of probabilistic property chains Markov so they do not use quantities but the possibilities values of the elements of the matrix transitional therefore increase the sample size (the number of views or the length of time) will result to reduce the marginalization of error limit (reducing the proportion of its existence), which leads us to raise the quality of the capabilities and increase the degree of confidence in them. 
The study came out a set of recommendations, including: the need to ensure the researchers increased diligence when recording views so as to reduce the likelihood of the emergence of an error in the registry, especially when using Markov chains.

- Study of (Alwan, 2007), entitled: Application of Markov chains in the field of communications using the simulation method.

The study aimed to identify the Markov chains and matrix Markov to determine prepare customers between companies in the future equilibrium and to identify the most important probability distributions used in the field of mobile phones and the means used to search is the matrix of Markov and how to calculate it by using the Markov method in determining the behavior of consumers after generating clients matrix first month and gain matrix of binomial distribution and then use them to calculate the steps Markov was used the simulations programming for use in the generation of data distributed Poisson distribution and the exponential distribution to determine the rate of telephone calls and longer time periods for calls and extract the average standard error through which is selected from business meals boxes of the Company is the best performance by reading less for meals. The study found a number of findings, including: the importance of the Markov method in determining the competition between the companies and the importance of the scientific method in determining the policy of companies.

- Study of (Al- Saadi, 2007), entitled: Fluctuations in the Iraqi dinar exchange rate for the period (1996 until mid 2005), and to predict its price in the future using Markov chains.

The study aimed to identify the identification Markov chains, as it is these chains of models upon which to predict the process, when data in the present time, and three cases are the rise, decline, stability, and between the past, present and future have been reached in this research to analysis my way of applying the maximum likelihood and least squares methods to estimate the transition probabilities matrix, and has a comparison between the two methods to find the difference between them, and were divided years in question into three phases based on political circumstances experienced by Iraq in addition to the public stage and include all stages. And found the results to be the third phase (the present) has coincided with the proposal of the Ministry of Finance, who pointed to raise the value of the Iraqi diner for a specific price, and it must be pointed out that he has been a drop in the exchange rate which is shown by this stage in the transition probabilities matrices for two ways, as was the case of stability is the top and then decline, which came in second place, and was the beginning of the decline on 16/11/2006 until 24/12/2006 discussion on the decline continues, which confirms the accuracy of the results of the transition probability matrix, which is reflected on the ground, In addition to the development of recommendations.

- Study of (Al-Ali, et al., 2009), entitled: Analysis of market movement using Markov chains: An Empirical Study on the following companies (company of spinning Hamah, company of spinning JbLha, company of Al-Walied spinning Hems).

The study aimed to identify the Markov chains to predict the future status of using the matrix transition probabilities of the previous case that will help determine cases of the system from time to time. It is the market analysis through quotas marketing for some of the companies (spinning Hamah company, Spinning JbLha company, Al-Walid Spinning Homs) and forecasting quotas marketing of previous companies in the coming period, or coming periods (one month), and the study found a number of findings, including: was spinning Hamah company's ability to retain as a percentage of its customers $(77 \%)$, while we find $(86 \%)$ with yarn protoplasm company, the Al-Walied spinning Homs was $(91 \%)$, and the share of yarn Hamah company in the month of January $(0.282)$ while we find in the protoplasm spinning company (0.303), while total (0.415) in the Al-Walied spinning Homs.

The study came out a set of recommendations including: The retention of all its customers the company's ability not only by the ability of companies in the market for innovation and creativity, and raise competitiveness, improve product quality, and lower their prices.

- Study of (Zein-Alabidien, 2009), entitled: Markov chains to reduce the risks that threaten the economic institutions.

This study aimed to detect the techniques that help institutions to predict to draw a vision for the future to enable them to avoid some of the risks and contain risks and deal with them, through various phenomena and the variables surrounding the study, and the study found several results, including: 


\section{Dr. Laith Abdallah Alqheiwi}

a. The Markov analysis of mathematical and analytical way to help the institution or the decisionmaker on the knowledge developed in the future and predicts the risk that you may encounter.

b. Helps analyze Markov economic institution in risk management that you may encounter through discovered before they occur.

The study came out a set of recommendations, including: the institution not only to study and repositioning during the current period only, but must have an outlook based on sound science. And the institution that relies on mathematical analysis in their risk assessment and forecasting as well as logical descriptive analysis and self-analysis Markov which may help a lot of institutions to know their status among the other institutions of the same activity as well as the various risks that may be encountered and then draw a list of effective strategies to uncertainty and accuracy.

- Study of (Hussein, 2009), entitled: The use of markov matrix in estimating the time of staying of the student in the Faculty of Law at the University of Damascus.

This study aimed to identify the importance of applying markov method to measure the time of staying of the student in each year at the college in general, and determine the number of graduates and forecasting of graduates numbers for 2010. Also the study aimed to reach a scientific and logical indicators can be embodied in practice in economic development plans to connect the output of higher education, and the study reached to the results of several of the most important: there is a strong relationship between the university and the community and it is very necessary to study this relationship scientifically accurate and provide possible trends for this relationship becomes clearly thought out.

The study came out a set of recommendations including: The markov matrix of the best means and ways in which sport can be used in forecasting the number of students at the university and certified, and then be seen in the development plans so as not to become there is no unemployment in the ranks of licensed rights.

\section{The Practical Part}

\subsection{The Study Data}

The study is mainly depend on the secondary data related to the movement of the HR selected from the annual reports of the Jordanian Banks (Arab Bank, Housing Bank, and Jordan Bank) for year (2014). To achieve the study objects, the researcher selects three Banks from the Jordanian Banks in order to choose a number of the employees, and the loss of employees. As shown in Table (1) the following:

Table1. The employees' movement between Banks and the employees number at the year (2014)

\begin{tabular}{|c|c|c|c|c|c|}
\hline Banks & Arab Bank & Housing Bank & Jordan Bank & $\begin{array}{c}\text { Loss } \\
\left(\mathbf{L}_{\mathbf{i}}\right)\end{array}$ & $\begin{array}{c}\text { Employees } \\
\text { Number }\end{array}$ \\
\hline Arab Bank & 0 & 24 & 15 & 39 & 6249 \\
\hline Housing Bank & 42 & 0 & 13 & 55 & 2199 \\
\hline Jordan Bank & 54 & 31 & 0 & 85 & 1769 \\
\hline
\end{tabular}

\subsection{Results and Discussion}

\subsubsection{Markov Matrix Estimation}

We can find the Markov matrix using the relations (1) and (2), as follows:

$\mathrm{P}=\left[\begin{array}{ccc}0.994 & 0.004 & 0.002 \\ 0.019 & 0.975 & 0.006 \\ 0.030 & 0.018 & 0.952\end{array}\right]$

The results of the Markov Matrix explained that:

a. The highest retention percentage was in favor of the Arab Bank with (0.994), followed by Housing Bank with retention percentage of (0.975), and followed by the Jordan Bank with retention percentage of (0.961).

b. The lowest total loss was in favor of the Arab Bank with (0.006), for Housing Bank by (0.004) and Jordan Bank by (0.002), also the total loss of Housing Bank is (0.025), and the total loss of Jordan Bank is (0.048). 


\subsubsection{Forecasting of the Market Shares of Banks}

Depending on the relations (3) and (4) we got the market shares at the years $(2015,2016)$ respectively. And depend upon the market shares; we can forecast the employees' number for Banks at the years $(2015,2016)$. As shown in Table (2) the following:

Table2. Market shares \& forecasting in the employees number for Banks at the years $(2015,2016)$

\begin{tabular}{|c|c|c|c|c|c|c|}
\hline \multirow{2}{*}{ Years } & \multicolumn{3}{|c|}{ Market Shares } & \multicolumn{3}{c|}{ Forecast in Employees Number } \\
\cline { 2 - 7 } & $\begin{array}{c}\text { Arab } \\
\text { Bank }\end{array}$ & $\begin{array}{c}\text { Housing } \\
\text { Bank }\end{array}$ & $\begin{array}{c}\text { Jordan } \\
\text { Bank }\end{array}$ & Arab Bank & $\begin{array}{c}\text { Housing } \\
\text { Bank }\end{array}$ & Jordan Bank \\
\hline 2014 & 0.612 & 0.215 & 0.173 & 6253 & 2197 & 1767 \\
\hline 2015 & 0.618 & 0.215 & 0.167 & 6314 & 2197 & 1706 \\
\hline 2016 & 0.623 & 0.215 & 0.162 & 6365 & 2197 & 1655 \\
\hline
\end{tabular}

\subsubsection{Determine of the Market Equilibrium Conditions}

After we solve the equations in the relations (7) and (8), we got the row vector of shares under the conditions of the market equilibrium, as follows:

$\underline{S}=\left[\begin{array}{lll}0.615 & 0.215 & 0.170\end{array}\right]$

Also, can determine the employees' number at the period of the market equilibrium conditions using the relation (8). As shown in Table (3):

Table3. Employees number in the period of the Market Equilibrium

\begin{tabular}{|c|c|c|}
\hline Banks & Shares $\mathbf{( S}_{\mathbf{i}}$ \%) & Employees Number \\
\hline Arab Bank & $61.5 \%$ & 6283 \\
\hline Housing Bank & $21.5 \%$ & 2197 \\
\hline Jordan Bank & $17.0 \%$ & 1737 \\
\hline
\end{tabular}

The results in Table (3), refers to the final result that the Jordan Bank and the Housing Bank it have lost (32) employees, (2) employees respectively, for the Arab Bank by (34) employees.

\section{Conclusions}

a. The results of the Transition Probabilities estimation, refers to the highest retention percentage was in favor of the Arab Bank, followed by the Housing Bank, and followed by the Jordan Bank.

b. The results of the Transition Probabilities estimation, indicates to the lowest total loss was in favor of the Arab Bank by (0.006), for Housing Bank and Jordan Bank.

c. The results of the estimation the employees number at the period of the market equilibrium, indicate that the Jordan Bank and the Housing Bank it have lost (32) employees, (2) employees respectively, for the Arab Bank by (34) employees.

\section{ACKNOWLEDGEMENT}

This research is funded by the Deanship of Research in Zarqa University/ Jordan.

\section{REFERENCES}

[1] Al-Ali I., et al., (2009), Analysis of Market Movement using Markov Chains: An Empirical Study on the companies (Company of spinning Hamah, Company of spinning JbLha, and Company of Al-walled spinning Hems), Tishreen University Journal for Research and Scientific Studies. 31(1): 175-178.

[2] Al-Bayaa M. M., (2003), Registry Errors in Markov Chains: An Empirical Study for Dairy Products, Market Research and Consumer Protection Center, Baghdad University.

[3] Alwan, H., (2007), Application of Markov Chains in the Field of Communications using the Simulation Method, Master Thesis (Unpublished), Faculty of Management and Economics, University of Baghdad, Iraq.

[4] Al- Saadi, K. B., (2007), Fluctuating of the Iraqi Diner Exchange Rate for the period (1996 Until Mid 2005), And Forecasting its in the Future by using Markov Chains, Master Thesis (Unpublished), Faculty of Management and Economics, University of Baghdad, Iraq.

[5] Al-Taai Y. H., (2006), Human Resources Management, Al-waraq Establishment. Amman, Jordan. 
[6] Barry R., Ralph M., and Stair J., (2000), Quantitative Analysis for Management, $7^{\text {th }}$ Edition, Prentice-Hall.

[7] Hussein, A., (2009), The use of Markov Matrix in Estimating the Time of Staying of the Student in the Faculty of Law at the University of Damascus, Syria.

[8] James, Walker, Human Recourses Planning, (2007), McGraw-Hill, USA.

[9] Kashwy, Barry, (2006), Human Resources Management, Dar-faruq for Publishing and Distribution, Egypt.

[10]Sirl D., (2005), Markov Chains: An Introduction-Review, University of Queensland Australia.

[11] Touama H.Y., (2009), Operations Researches: Models \& Applications, Dar-safa for Publishing and Distribution, Amman, Jordan.

[12] Touama H.Y., (2015), Application of Markovian Models and Transition Probabilities' Matrix to Analyze the Workforce Movement in Jordanian Productivity Companies, PARIPEX- Indian Journal of Research, 4(6): 215-218.

[13] Zein-Alabidien B.A., (2009), Markov Chains to Reduce the Risks that Threaten the Economic Institutions.

\section{AUTHOR's BIOGRAPHY}

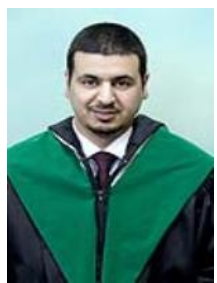

Dr. Laith Abdallah AlQhaiwi, Faculty member in the Department of Business Administration Faculty of Economics and Administrative Sciences at the ZARQA University Author of many researches in several international journals 